DECOLONIALITY AND INTERCULTURALITY: THEORETICAL-METHODOLOGICAL ASSUMPTIONS FOR THE EDUCATION OF THE ETHICORRACIAL RELATIONS IN THE TEACHING OF HISTORY

\author{
DECOLONIALIDAD E INTERCULTURALIDAD: PRESUPUESTOS TEÓRICO- \\ METODOLÓGICOS PARA LA EDUCACIÓN DE LAS RELACIONES \\ ETNICORRACIALES EN LA ENSENANZA DE HISTORIA
}

Elison Antonio Paim elison0406@gmail.com

Odair de Souza odairdesouza@gmail.com

\title{
REVISTA PEDAGÓGICA
}

Revista do Programa de Pós-graduação em Educação da Unochapecó | ISSN 1984-1566 Universidade Comunitária da Região de Chapecó | Chapecó-SC, Brasil Como referenciar este artigo: PAIM, E. A.; SOUZA, O. Decolonialidade e interculturalidade: pressupostos teórico-metodológicos para a educação das relações étnicorraciais no ensino de história. Revista Pedagógica, Chapecó, v. 20, n. 45, p. 90-112, set./dez. DOI: http://dx.doi.org/10.22196/rp.v20i45.4492

\begin{abstract}
RESUMO: Este artigo é fragmento oriundo da dissertação desenvolvida no Programa de Mestrado Profissional em Ensino de História - Profhistória da Universidade Federal de Santa Catarina como o título A educação para as relações étnicorraciais e o ensino de história: memórias e experiências de docentes da educação básica. Neste recorte apresentamos um diálogo com os documentos legais para o Ensino de História e Cultura Afro-brasileira e Africana. Dentre outros destacamos a Lei 10.639/2003 que trata da obrigatoriedade do ensino de história e cultura afro-brasileira e africana nas escolas, as Diretrizes Curriculares Nacionais para a Educação das Relações Étnicorraciais - Dcneer. Para análise nos pautamos na decolonialidade (do poder, do saber, do ser) como uma possibilidade epistemológica radical para o rompimento com os saberes eurocêntricos e numa nova metodologia e práticas pedagógicas fundamentadas na interculturalidade. Focamos de forma particular como o ensino de história poderá contribuir para gerar questionamentos, problematizações e aberturas para se ensinar para além da história dos povos europeus ou histórias narradas de forma colonizadora com modelos europeus.
\end{abstract}

Palavras-chaves: Ensino de História. Lei 10.639/2003. Decolonialidade. Interculturalidade.

ABSTRACT: This article is a fragment from the dissertation developed in the Professional Master 's Program in Teaching History - Profhistory of the Federal University of Santa Catarina as thetitleEducation for ethno - racial relations and the teaching of history: memories and experiences of teachers of basic education. In this section we present a dialogue with the legal documents for the Teaching of Afro-Brazilian and African History and Culture. Among others, we highlight Law 10.639 / 2003, which deals with the compulsory teaching of AfroBrazilian and African history and culture in schools, the National Curricular Guidelines for the Education of Ethnicoracial Relations - Deneer. In order to analyze, we use decoloniality (power, knowledge, and being) as a radical epistemological possibility for the break with Eurocentric knowledge and in a new methodology and pedagogical practices based on interculturality. We focus in particular on how history teaching can contribute to generate questions, problematizations and openings to teach beyond the history of European peoples or stories narrated in a colonizing way with European models.

Keywords: History teaching. Law 10.639 / 2003. Decoloniality. Interculturality.

RESUMEN: Este artículo es fragmento oriundo de la disertación desarrollada en el Programa de Maestría Profesional en Enseñanza de Historia - Profhistoria de la Universidad Federal de Santa Catarina como el título La educación para las relaciones étnicas y la enseñanza de la historia: memorias y experiencias de docentes de la educación básica. En este recorte presentamos un diálogo con los documentos legales para la Enseñanza de Historia y Cultura Afrobrasileña y Africana. Entre otras destacamos la Ley 10.639 / 2003 que trata de la obligatoriedad de la enseñanza de historia y cultura afrobrasileña y africana en las escuelas, las Directrices Curriculares Nacionales para la Educación de las Relaciones Étnicoraciales - Dcneer. Para el análisis nos fijamos en la decolonialidad (del poder, del saber, del ser) como una posibilidad epistemológica radical para el rompimiento con los saberes eurocéntricos y en una nueva 
metodología y prácticas pedagógicas fundamentadas en la interculturalidad. Enfocamos de forma particular cómo la enseñanza de la historia puede contribuir a generar cuestionamientos, problemas y aperturas para enseñar más allá de la historia de los pueblos europeos o historias narradas de forma colonizadora con modelos europeos.

Palabras claves: Enseñanza de historia, Ley 10.639 / 2003. Decolonialidad. Interculturalidad.

Ao promover uma multiplicidade de vozes o que se quer, acima de tudo, é quebrar com o discurso autorizado e único, que se pretende universal.

(Djamila Ribeiro, 2017, p.70)

A história é um componente curricular que no Brasil, historicamente esteve aliado aos mais diferentes interesses governamentais. Assim, durante boa parte da história do Brasil, esta área do conhecimento esteve vinculada à necessidade dos governos ter um ensino de história atrelado a idéia de construção da nação.

Nos primeiros tempos de escolarização no Brasil não havia o conceito de ensino de História e/ou História como disciplina escolar. O que havia era a História ministrada pelos sacerdotes da Igreja Católica que ensinavam história vinculada ao ensino religioso. Bittencourt (1993, p. 144) ao abordar o tema, afirma que:

o estudo de História para o nível secundário antes de se tornar um corpo de conhecimento sistematizado com objetivos específicos, possível de ser ensinado e transmitido nas escolas públicas era um simples anexo ou complemento do latim, disciplina todo-poderosa na concepção de currículo "humanístico" ou "literário". Pela versão do ensino convencional, a História limitava-se a um ensino integrante do ensino religioso.

Dessa forma, era um estudo de história estritamente vinculado à Igreja católica, portanto, uma História Sagrada. Porém, no Brasil Império este modelo de estudo de História sofreu um abalo, pois segundo Circe Bittencourt (1993, p. 194), "parte dos intelectuais pretendia construir uma história laica, uma espécie de "ciência Social" da nação que se criava sob a dominação de um estado independente, mas não desejava abolir os princípios educativos da Igreja Católica".

Surge, portanto um tensionamento, entre o ensino de História ministrado pela Igreja Católica e os oferecidos pelo Estado Imperial que tinha como objetivos usar o estudo da História para favorecer a construção da nação e a ideia de uma identidade nacional. Dialogamos com Caimi (2001, p. 28) para quem a "História não constituía apenas uma disciplina escolar e sua inserção era considerada indispensável em todas as camadas sociais e faixas etárias uma vez 
que tinha o papel de formar os juízos de valor e o patriotismo, necessários a constituição da identidade nacional". Para a autora as propostas para o ensino de História no início do Brasil republicano assumiram outra configuração diferente das do Brasil Império para atender aos interesses do estado nacional republicano, o qual estava preocupado em forjar uma identidade nacional na qual todos/as brasileiros/as fossem agrupados em única forma de pensar, de ser, de existir e estar no mundo.

Após a proclamação da República (1889) entre avanços e recuos da democracia ainda em processos de construção no país, aconteceu o golpe militar (1964) e então, uma vez mais, a História e o ensino de História foram estruturados visando atender aos interesses do regime político implantado de forma autoritária. O regime militar, entre outras ações, diminuiu o tempo das licenciaturas em História, formando os chamados cursos de licenciaturas de curta duração que habilitava o/a professor/a para lecionar História, Geografia, Educação Moral e Cívica (EMC) e Organização Social e Política Brasileira (OSPB). Com isso, "havia uma intenção deliberada de desqualificar e desvalorizar os professores de $1^{\mathrm{O}}$ e $2^{\mathrm{O}}$ graus, encurtando sua formação e destituindo-o de qualquer senso crítico, sobretudo, pela total negação da pesquisa como atividade necessária à sua formação”. (CAIMI, 2001, p. 42).

O modelo de história a ser seguido era o eurocêntrico. Não havia neste ensino, espaço para a diversidade étnicorracial que constitui a sociedade brasileira. Assim, os povos africanos, afro-brasileiros e indígenas eram quase que completamente invisibilizados neste ensino e/ ou se eram apresentados eram de maneira exótica e folclorizada.

Ziliotto (2016, p. 52) ao refletir sobre isso pondera que:

Então qual seria o lugar ocupado pela História das Áfricas dos povos afro-brasileiros? [...] Nossa construção disciplinar está carregada de um contexto de produção da modernidade que aqui entendemos como o outro lado da colonialidade. Ou seja, os parâmetros que definem o que deve ser ensinado, como se ensinar e para que ensinar tem íntima relação com os cânones ocidentais.

A disciplina escolar História, até então, no contexto do Brasil Contemporâneo, foi e, é, em grande parte ensinada nos princípios epistemológicos do colonizador branco, europeu. Neste sentido, outros saberes e dizeres, ou seja, outras narrativas foram omitidas e silenciadas no ensino de história, traduzindo assim uma história que não contempla a diversidade sóciorracial da nação brasileira. Meyer (2017) ao pensar sobre essas questões e, sobretudo sobre as populações indígenas na constituição da nação afirma que

nega-se a inserção do protagonismo de povos e culturas que não se vinculam a estrutura 
1 A Lei 10.639/2003 alterou a Lei 9.394/96, a LDB (Lei de Diretrizes e Bases de Educação Nacional) para incluir o artigo que obriga o ensino de história e cultura afro-brasileira e africana em todo o sistema de ensino do país. Posteriormente a lei 11.645/2008 modificou a lei 10.639/2003 para incluir a história e cultura dos povos indígenas.

2 Entende-se por desigualdade racial "toda situação injustificada de diferenciação de acesso e fruição de bens, serviços e oportunidade nas esferas pública e privada em virtude da raça, cor, descendência ou origem nacional ou étnica. (artigoo $1^{\circ}$, inciso $2^{\circ}$ da Lei ${ }^{\circ} 12.228$, de 20 de julho de 2010). narrativa europeia em suas próprias histórias. Outra consequência do não deslocamento das narrativas eurocêntricas é a destituição da dignidade da memória de outras identidades e o não reconhecimento dos vínculos sociais que amarram as sociedades indígenas a outras culturas no presente. Essas práticas de exclusão são resultados e ao mesmo tempo resultam em duas formas de genocídio: o epistemicídio e a morte física que perenizam a violência colonial. (MAYER, 2017, p. 21).

Assim, Ziliotto (2016) e Meyer (2017) discutem as dificuldades que o ensino de história teve em invisibilizar histórias e culturas de outros povos como os indígenas e, em particular, os africanos e afro-brasileiros. Porém, ao longo do tempo, os movimentos sociais de indígenas e negros lutaram e continuam lutando para que suas histórias e culturas sejam incluídas como conteúdos obrigatórios no ensino de história nas escolas públicas e privadas de todo o país.

No bojo da discussão para a elaboração da constituição de 1988, esses movimentos ganharam força na constituinte e os parlamentares inseriram então na Constituição - embora não obrigatórios - artigos que garantissem o ensino de história e culturas indígenas e afro-brasileiras nos currículos.

Este ensino para a cidadania não estaria completo se não houvesse espaço nos currículos e na escola de educação básica para os estudos de história e culturas africanas e afro-brasileiras. Para que isso acontecesse e essas populações ganhassem visibilidade e destaque nos currículos escolares, mais uma vez por força dos movimentos sociais e, em especial, os movimentos negros, foi homologada em o9 de janeiro de 2003, a lei $10.639^{1}$ que trata da obrigatoriedade do ensino de História e culturas africana e afro-brasileira nas escolas públicas e privadas de todo o país.

Porém, pesquisas realizadas no Brasil como as de Hasenbalg (1992; 2005), Cavalleiro (1998), Fernandes (2008), demonstram que as desigualdades raciais ${ }^{2}$ no Brasil ainda são enormes e, sobretudo, que esta desigualdade atinge em cheio as escolas de todos os níveis de ensino de nosso país: da educação básica ao ensino superior.

Desigualdades raciais estas manifestadas entre outros aspectos pela não inserção da história da África e da cultura afro-brasileira nos currículos - quando temos mais de $50 \%$ da população que se identifica como negra ou parda (que tem ascendência africana) -, não sejam abordadas em nossas salas de aula. Ou que, ainda somos um país racista, apesar de na nossa formação sócio-histórica pautada na escravização forçada e violenta, um contingente enorme de povos africanos que juntamente com os indígenas que aqui estavam compõe a nossa sociedade e cultura. Desigualdades raciais que colocam a população negra nos piores índices de desigualdades no trabalho e de salário em nosso 
país em relação aos brancos e que também colocam nossas crianças, adolescentes e jovens negros nas piores situações de escolaridade e desempenho escolar.

Dessa forma, a desigualdade racial e o racismo ainda hoje estão manifestos em vários aspectos da sociedade, na mídia, sobretudo a televisiva na qual os negros e negras, na maioria das vezes, só aparecem na condição de trabalhadores domésticos, marginais, bandidos, entre outros personagens subalternos; nos espaços públicos nos quais são encarados e xingados, no esporte, enfim, em vários momentos de suas vidas o/a negro/negra em sua maioria possivelmente já passou por algum episódio de racismo e discriminações.

$\mathrm{Na}$ escola, isto também se percebe fortemente: seja nas práticas racistas dos colegas, seja nas "brincadeiras e piadas" preconceituosas, na invisibilidade de suas histórias e culturas, nos livros didáticos, na omissão da escola enquanto instituição de ensino em trabalhar temáticas relacionadas ao racismo e aos preconceitos, enfim, numa série de mecanismos que invisibilizam completamente a presença das histórias e culturas negras em todo o âmbito do currículo escolar.

Debater educação para as relações étnicorraciais nas unidades de ensino de nosso país não é tarefa fácil. Isto porque ainda convivemos com currículos, livros didáticos e formações universitários ou de capacitação marcadamente eurocêntricos. Além disso, nossa sociedade resolveu esconder dela mesma esses distúrbios criados ao inviabilizar, por conta da chamada miscigenação racial, o preconceito e o racismo tão presentes nos dias atuais, apesar de 130 anos do fim da escravidão. Essa distorção criada pela sociedade brasileira, entre outras coisas, permitiu um pensamento completamente estereotipado do continente africano e de todas as suas gentes.

Aliado a essa configuração da sociedade brasileira, somos vítimas de um currículo escolar completamente eurocêntrico que desconsidera ou minimiza ao máximo as informações sobre os povos indígenas, africanos e afro-brasileiros, omitindo suas histórias, culturas, saberes e fazeres.

Pereira (2017) ao discorrer sobre o currículo eurocêntrico da História defende que o modelo quadripartite de organização em História antiga, medieval, moderna e contemporânea transfere-se como se todos os lugares do mundo tivessem vivido a História da Europa. Nessa perspectiva, evidencia-se seu caráter racista que busca silenciar histórias e esse silenciamento contribui para que determinados conteúdos sejam ocultados do currículo escolar de História.

Numa tentativa de minimizar esse racismo violento e silenciado, o governo brasileiro, motivado por forte pressão dos movimentos negros, tem, ainda que timidamente, procurado colocar a problemática do racismo e dos preconceitos em seus documentos curriculares. 
Assim, a lei de Diretrizes e Bases de Educação Nacional no 9394/96 já em seu artigo $26 \S 4^{\circ}$ sinalizam essas contribuições citando que "O ensino da História do Brasil levará em conta as contribuições das diferentes culturas e etnias para a formação do povo brasileiro, especialmente das matrizes indígena, africana e europeia". (Grifo nosso) bem como os Parâmetros Curriculares Nacionais (Brasil, 1998) e, posteriormente em 2003 a aprovação da Lei 10.639/2003 que instituiu a obrigatoriedade (grifo nosso) do ensino de história e culturas africanas e afro - brasileiras nos estabelecimentos de ensino públicos e privados no Brasil e, em seguida, são instituídos as "Diretrizes".

Porém, conforme tem evidenciado diversos estudos e pesquisas, (BORGES, 2004; SANTOS, 2010; PEREIRA, 2010; DIAS, 2011; PAULA, 2013, PASSOS, 2014) a implementação da lei 10.639/2003 tem encontrado forte resistência em sua implantação nas unidades escolares de todo o país. Dentre estes autores, Oliveira (2010) investigou a formação de professores em História da África e das culturas africanas e afro-brasileiras bem como a aplicação da lei 10.639/2003 e as diretrizes curriculares para a educação das relações étnico-raciais e para o ensino de história e culturas africanas e afro-brasileiras, via promoção de um Curso de História da África em parceria com o Sindicato Estadual dos Profissionais da Educação do Rio de Janeiro - SEPE. Entre os participantes deste curso, constatou que ainda há muitas dúvidas e questionamentos em relação a este tema por parte dos profissionais de educação e que, portanto, essas novas abordagens ainda não chegaram às salas de aula.

Em Santa Catarina, o artigo da professora Joana Célia dos Passos (2014) nos revela a partir de uma pesquisa feita em 2011, em dez Universidades Públicas e comunitárias de Santa Catarina nos cursos de licenciaturas em História e Pedagogia que a implementação da Lei 10.639/2003 e a educação das relações étnico-raciais ainda andam a passos muito lentos. Afirma ela que,

percebemos que a educação das relações étnico-raciais e a história e cultura afro-brasileira e africana ainda ocupam lugares periféricos no currículo dos cursos de pedagogia oferecidos em SC. A complexidade e a história das relações étnico-raciais no Brasil é que ainda motivam tamanha dificuldade na inserção e abordagem destes conhecimentos na formação docente (PASSOS, 2014, p.181)

Nesse sentido, percebemos que também o Estado de Santa Catarina e os municípios ainda têm uma divida histórica com a população negra brasileira, pois continuam inviabilizando ou se omitindo do debate na formação de professores e/ ou a execução de propostas efetivas em sala de aula.

Por isso, alguns questionamentos ainda permanecem: porque passados mais de dez anos da promulgação da 
lei e das Diretrizes, sua implementação e execução ainda são quase inexistentes em muitas escolas? O que favorece esse silenciamento?

As pesquisas dos autores/as já mencionados indicam uma série de fatores entre eles o histórico racismo presente na sociedade brasileira desde a colonização e que, há ainda a justificativa da falta de materiais nas unidades escolares que vão desde livros didáticos até bibliotecas bem estruturadas e equipadas, ainda há pouca ou nenhuma formação do professor para abordar estes temas, enfim, uma série de motivos citados para justificar a ausência da aplicação da lei 10.639/2003 e das Diretrizes em muitas das escolas.

Para além das condições estruturais da maioria das escolas do Brasil (falta de bibliotecas e/ ou de bibliotecas atualizadas, de salas de informática, de profissionais) somado as condições de trabalho dos docentes (expressa em jornadas exaustivas, salários baixos, sem uma política efetiva de formação continuada, associado à alta rotatividade de professoras/es em escolas públicas), outros dois fatores que influenciam para que não aconteça a implementação de uma efetiva Educação para as relações étnico-raciais e consequentemente da história e cultura afro-brasileira e africana nas escolas é a branquitude e a chamada democracia racial e, como consequência desses dois, o racismo.

A branquitude não permite ao sujeito de identidade racial branca se identificar como detentor de privilégios por ser branco e isto potencializa a suposta não necessidade de se estudar temáticas raciais nas escolas e nas salas de aula. A branquitude não nos permite nos enxergarmos como sujeitos brancos racializados sociologicamente falando e, que por isso "naturalmente" dispõe de privilégios.

A branquitude tem sido objeto de estudos de diversos pesquisadores entre eles, invocamos aqui o diálogo com Lia Schucman (2014, p. 56) para definir que "branquitude é entendida como uma posição em que sujeitos que ocupam esta posição foram sistematicamente privilegiados no que diz respeito ao acesso materiais e simbólicos, gerados inicialmente pelo colonialismo e pelo imperialismo e que se mantêm e são conservados na contemporaneidade".

Esta posição de privilégios concebida pelos sujeitos brancos produz sentimentos de superioridade que fazem com que não seja estudado, por exemplo, histórias e culturas outras na escola, invisibilizasse assim, outros povos e culturas. Cardoso (2010, p. 611) complementa dizendo que "a branquitude é um lugar de privilégios simbólicos, subjetivos, objetivos, isto é, materiais palpáveis que colaboram para a construção social e reprodução do preconceito racial, discriminação racial "injusta" e racismo". Esta manutenção de privilégios iniciada no colonialismo e que se prolonga aos dias atuais se reproduz em vários espaços sociais e entre eles, a escola.

A escola tem se constituído como um lugar de práticas preconceituosas e discriminatórias quando não problematiza o currículo eurocentrado, branco, masculino, 
cristão e, portanto, racista. Quando não se debatem relações raciais na escola, ou quando não se oportuniza que outras pessoas, sejam elas brancas ou negras o façam. Quando, enfim, estes temas não ganham espaço na unidade escolar. No entanto, existem negros/negras e brancos/brancas que tentam fazer uma educação antirracista. Quando utilizamos o termo branco antirracista nos inspiramos em Cardoso, para chamar esse branco de branco crítico. Cardoso enumera a presença de dois tipos de brancos. Assim, para Cardoso (2017, p.33) "branquitude crítica é aquela pertencente à indivíduos ou grupos de brancos que desaprovam publicamente o racismo. Por outro lado, nomeei como branquitude acrítica a identidade branca individual ou coletiva que argumenta a favor de uma superioridade racial. De modo geral, os brancos antirracistas, exemplificam a branquitude crítica”.

Assim, ao dialogarmos com Cardoso, evidenciamos que a branquitude acrítica é o que tem prevalecido na sociedade e, em especial nas escolas, pois os brancos acríticos, além de serem racistas, ainda não querem "desaprender" o racismo, desconstruir a secular história de invisibilização e inferiorização dos povos negros e indígenas na sociedade brasileira e, por consequência não quer lutar por uma sociedade mais equânime.

Deduzimos assim que a escola poderá ser um local de presença de docentes críticos que condenam o racismo e assumam posturas antirracistas. Precisamos entender que ao não visibilizar história e culturas de povos negros e indígenas está perpetuando a violência racial e consequentemente assumindo a supremacia branca.

Para que a escola fortaleça a necessidade de uma educação para as relações étnicorraciais, precisa além de desconstruir a branquitude como algo naturalizado em que os privilégios de pessoas brancas são encarados com tranquilidade em seu espaço, a escola precisa desconstruir também outro aspecto que trava uma efetiva educação para as relações étnicorraciais, ou seja, a ideia do mito da democracia racial.

Este mito, forjado e reforçado pelas elites intelectuais brancas brasileiras, a partir do clássico livro "Casa-grande e senzala" de Gilberto Freyre (2016) nos incentivou e nos incentiva ainda a pensar que os principais componentes étnicos formadores da nação brasileira e, em especial, os brancos e negros vivem em harmonia, não prevalecendo superioridade racial entre eles. Domingues (2004, p. 276) afirma que a "rigor significaria um sistema racial desprovido de qualquer barreira legal ou institucional para a igualdade racial e em certa medida, um sistema racial desprovido de qualquer manifestação de preconceito ou discriminação".

No entanto, sabe-se que não é bem assim que aconteceu e que acontece. A sociedade brasileira a despeito de viver a suposta democracia racial praticava e ainda pratica atos preconceituosos, discriminatórios e marcadamente racistas 
E ainda, se formos investigar na contemporaneidade, verificamos que a tal democracia racial existe de maneira falaciosa, pois há consideráveis evidências de evasão de crianças negras do ambiente escolar, inumeráveis casos de assassinatos pela polícia de jovens negros/negras, salários mais baixos pagos as populações negras, em particular as mulheres, enfim, a situação da população negra brasileira na atualidade, se não é análoga a mesma de 1888, é semelhante em muitos aspectos.

Portanto, essas duas ideias, a naturalização da branquitude e o não questionamento do branco enquanto detentor de privilégios por ser branco e a democracia racial alicerçada e endossada por professores e gestores acabam por naturalizar e reforçar o racismo.

O racismo, persistente ainda no Brasil, é fruto de uma sociedade escravocrata, que violentou, inferiorizou e subalternizou os povos africanos e afro-brasileiros e, além disso produziu subjetividades nos seres violentados, pois entendemos em diálogo com Miranda, Toledo e Andrade (2018, p.54) que "o racismo é um elemento de produção de subjetividades que afeta diretamente os modos de ser e estar no mundo da população brasileira, perpassando a produção intelectual, plataformas políticas e a construção e a mobilização de afetos".

Portanto, a partir do conceito de branquitude percebemos o quanto ele é mais do que uma ideologia. Ele é uma visão de mundo. Ele produz subjetividades, ou seja, ele constrói no psicológico de pessoas brancas como seres superiores, melhores, intelectualizados, civilizados em detrimento a outros povos, como indígenas, africanos e afro-brasileiros que seriam não civilizados, inferiores, incapazes. Muitas dessas ideias e subjetividades infelizmente são construídos ou reforçados a partir das escolas e assim, temos o que se convencionou chamar segundo Rodrigues (2011, p. 1) de "racismo educacional."

Observa-se, portanto, que o racismo, construído social e historicamente, perpassa toda nossa história, chegando a todos os espaços sociais: igreja, família, imprensa, política e, escola, foco principal dessa pesquisa. Mas, pensamos que a lei 10.639/2003 veio nos auxiliar e nos motivar a compreender outras culturas e histórias diferentes das eurocentradas e a nos estimular a práticas pedagógicas antirracistas. Por isso, dialogamos com Pereira (2012, p. 116) quando afirma a necessidade da construção de um currículo que,

apresente as histórias e culturas de todas as matrizes formadoras de nossa sociedade, considerando-as todas importantes e complementares, [...] e para que isso seja possível, é preciso que as histórias da África e dos africanos e a história da população negra no Brasil em toda a sua complexidade sejam pesquisadas e trabalhadas nas salas de aulas de História. 
Diante dos estudos que apontam o racismo e o preconceito existente nas escolas, bem como as dificuldades para se implantar estudos da história e cultura afro-brasileira e africana nos currículos, questionamos: por que a dificuldade de se implementar tais temas nos currículos das escolas, bem como a educação para as relações étnicorraciais? Seria isso falta de conhecimento do que é educação para as relações étnicorraciais? Quais os princípios, metodologias da educação para as relações étnicorraciais? Ela difere da educação convencional formal?

Como se observa nestes estudos e em pesquisas mais recentes no Brasil, a educação étnicorracial tem se mostrado uma tarefa difícil para muitos docentes que querem implementá-la para promover uma escola mais plural, diversa e democrática. Para responder a alguns questionamentos referentes a esta temática, muitos pesquisadores tem se debruçado sobre este assunto, alguns antes de lei 10.639/2003 como Cavallero (2001) e outros depois da mesma, como Gomes (2008; 2013) e Silva (2011) na tentativa de proporcionar possíveis respostas para estas indagações.

A educação para as relações étnicorraciais apresenta-se à frente da lei, no sentido de que ela é de suma importância para relações mais positivas na escola, pois é por meio dela que muitos educadores tentarão nas suas diversas escolas e salas de aulas minimizar e, se possível, dirimir por completo o racismo, o preconceito e a discriminação que vitimiza as populações deste país, principalmente a negra. Porém, para muitos educadores e educadoras não é fácil realizar esta tarefa devido às estruturas de dominação ideológica presentes na sociedade brasileira e, principalmente por falta de conhecimento desses temas em suas formações iniciais. Alguns outros/as ainda defendem que não há nas escolas espaço para este tipo de debate veiculando este tipo de ensino e debate aos antropólogos, sociólogos, etc. Gomes (2008) pondera que

tal argumento demonstra uma total incompreensão sobre a formação histórica e cultural da sociedade brasileira. E, ainda mais esta informação traz de maneira implícita a idéia de que não é de competência da escola discutir temáticas que fazem parte do nosso complexo processo de formação humana. Demonstra também a crença de que a função da escola está reduzida a transmissão de conhecimentos historicamente acumulados, como se estes pudessem ser trabalhados de maneira desvinculada da realidade social brasileira. (GOMES, 2008, p. 142)

Cumpre, portanto, aos educadores, rever seu papel enquanto agentes de transformação social e buscar formas pedagógicas eficazes para trabalhar as relações étnicorraciais ou uma educação antirracista. Mas, o quê seria uma educação para as relações étnicorraciais e, como proceder 
em uma escola que, na imensa maioria das vezes, só valoriza o elemento branco em seu espaço? Silva, responde o questionamento salientando que

a educação para as relações étnico-raciais tem por alvo a formação de cidadãos, mulheres e homens empenhados em promover em condições de igualdade no exercício de direitos sociais, políticos, econômicos os direitos de ser, viver, pensar próprios aos diferentes pertencimentos étnico-raciais. Em outras palavras, persegue o objetivo precípuo de desencadear aprendizagens e ensinos em que se efetive a participação nos espaços públicos. Isto é, em que se formem homens e mulheres comprometidos com e na discussão de questões de interesse geral, sendo capazes de reconhecer e valorizar visões de mundo, experiências históricas, contribuições dos diferentes povos que tem formado a nação bem como negociar prioridades, coordenando diferentes interesse, propostas, desejos, além de propor políticas que contemple efetivamente à todos. (SILVA, 2011, p. 12)

Enfim, educar para as relações étnico-raciais envolve reflexão, contato, diálogo, respeito, conhecimento e o estudo das histórias e culturas africanas, afro-brasileiras e indígenas. Deve reconhecer que a diversidade devem ser conhecidos e valorizados como elemento propulsor de ações pedagógicas humanas que contemple à todos e a todas.

Educar para as relações étnicorraciais vai além de corrigir os livros didáticos para incluir história e cultura africana e afro-brasileira, de discussão de mudanças no currículo, de processos ideológicos de politização do professor. Porém, muito mais do que isso, como as dimensões da ética, das identidades, das diversidades, das sexualidades e das relações raciais devem ser dimensões presentes no trato com a educação para as relações étnico-raciais.

No entanto, para que este processo aconteça, ou seja, para que haja um desenvolvimento efetivo de implementação de práticas antirracistas nas escolas é preciso que os docentes, os gestores, enfim, toda a comunidade escolar reconheça que o racismo está presente em todos os âmbitos da sociedade brasileira; a escola deve estar interessada em desenvolver estratégias e mecanismos para o seu combate; reconhecer que o racismo tem seus desdobramentos como a violência física, simbólica, psicológica e gera exclusão social, evasão escolar, entre outros e se esforce para (re) conhecer os conceitos básicos de uma educação antirracista como racismo, preconceito, discriminação. Se a escola não conhece estes conceitos, a educação para as relações étnicorraciais não acontece. Por outro lado, se a escola reconhece que o racismo existe e deseja combatê-los uma das formas de fazê-lo é conhecer e implementar a lei 10.639/2003 bem como suas Diretrizes. Esta lei que veio das demandas apresentadas, sobretudo, pelos movimentos 
negros é um instrumento não só de mais uma lei para se implementar em sala de aula ou na unidade escolar, "mas sim uma política de ação afirmativa e uma política de estado no campo educacional". (GOMES, 2008, p.80)

A lei trouxe uma série de inovações como possibilidades de mudanças ante a História; importante por possibilitar uma distribuição igualitária entre os conteúdos incluindo a história do continente africano em todos os seus aspectos; mas, o mais importante para a educação brasileira é o fato de ela trazer também mediante as Diretrizes uma educação para as relações étnicorraciais que vai além da mera incorporação de conteúdos africanos e afro-brasileiros nos currículos. Segundo Gomes,

a discussão sobre a África e a cultura africana e afro-brasileira encontra em um campo mais amplo: a educação para as relações étnico-raciais. Talvez seja essa a novidade mais interessante que as diretrizes trazem. A discussão sobre a questão africana e afro-brasileira só terá sentido e eficácia pedagógica, social e política se for realizada num contexto de educação para as relações étnico-raciais (GOMES, 2013, p. 81).

A autora também indica que a legislação se não for bem implementada pode trazer alguns equívocos que devem ser evitados numa educação antirracista como, por exemplo, fazer projetos pedagógicos para serem socializados somente na semana da Consciência Negra, ou deixar a educação das relações étnicorraciais somente para as disciplinas de História, Arte e Literatura, sendo que a legislação determina que deva ser permeada em todo o currículo escolar. Por outro lado, não relacionar a conquista da lei como mais um dos mecanismos de conquista do povo negro contra o apagamento de suas histórias e culturas e que esta conquista foi um processo histórico que resultou na lei e nas diretrizes e complementa reiterando que

a interpretação equivocada da lei também pode resultar em ações desconexas nas escolas que tendem a folclorizar a discussão sobre a questão racial como, por exemplo, chamar um grupo cultural para jogar capoeira, sem nenhuma discussão com os alunos/as sobre a corporeidade negra; realizar uma vez por ano um desfile da beleza negra, sem conectar a uma discussão mais profunda sobre a estética afro-brasileira; colocar os alunos/as da educação infantil para recortar pessoas negras de revistas étnicas e realizar trabalhos em sala ou enfeitar o mural da escola sem problematizar o que significa a presença dos negros na mídia; chamar os jovens do hip hop para participar de uma comemoração na escola, desconsiderando os alunos e alunas da própria instituição escolar neste movimento; tratar o dia 20 de novembro como mais uma data 
3 O grupo é formado predominantemente por intelectuais da América Latina e apresenta um caráter heterogêneo e transdisciplinar, compondo seu grupo figuras como: Enrique Dussel, Aníbal Quijano, Walter Mignolo, Ramon Grosfoguel, Catherine Walsh, Nelson Maldonado-Torres, Arturo Escobar, entre outros. Tem como categorias de análises o conceito de deconialidade, bem como mito da fundação da modernidade, colonialidade (do poder, do ser, do saber e da natureza), o racismo epistêmico, a geopolítica do conhecimento, a diferença colonial, o pensamento liminar, a transmodernidade e a interculturalidade crítica. (OLIVEIRA, 2012, p. 41). comemorativa, sem fazer articulação com uma discussão sobre o processo de lutas e resistências negras. (GOMES, 2013, p. 86).

Isto nos leva a conclusões de que para praticarmos a educação para as relações étnicorraciais precisamos nos reeducar e reestruturar nossos pensamentos e nossa formação profissional para não cairmos nos equívocos e mesmos erros de estudar as culturas africanas e afro-brasileiras pelo viés colonial e eurocêntrico.

Portanto, fica a pergunta: é possível aos docentes da educação pública e privada pensar o ensino para a educação das relações étnicorraciais e o ensino de história e cultura africana e afro-brasileira para além da matriz colonial europeia e subverter esta epistemologia por outras, que considere as histórias de todos esses povos e populações subalternizados por esse pensamento hegemônico ao longo dos séculos? Segundo o grupo de pesquisadores latino-americanos denominados modernidade/colonialidade ${ }^{3}$ : Sim. É possível.

O grupo modernidade/colonialidade pensa a América Latina a partir dela mesma e nos fornece elementos para compreendermos como a Europa se tornou o "centro do mundo" subalternizando e invisibilizando "mundos outros".

Pensar a radicalidade da colonialidade do poder, do saber, do ser é desconstruir as propostas pedagógicas eurocentradas ou pelo menos mostrar suas fragilidades para desconstruir o racismo, o preconceito e a discriminação. Advém daí a necessidade de se construir propostas e currículos outros nos quais essas populações sejam contempladas em suas dimensões históricas, culturais, políticas, sociais e afetivas.

Neste sentido, o Sociólogo peruano Quijano (2007) propõe estudar a colonialidade do poder como um sistema de representação construído para destacar a Europa no cenário mundial. Quijano (2005) nos informa ainda que esta colonialidade do poder nasce com a conquista das Américas, que segundo ele, não se dá somente do ponto de vista militar, iniciada no século XV, mas também conquistaram e introjetaram subjetividades nas populações dominadas, que se mantém mesmo depois da descolonização dos países latino-americanos, asiáticos a africanos, nos processos de independências dos séculos XIX e XX. Quijano afirma que a "colonialidade é um dos elementos constitutivos do padrão mundial capitalista. Funda-se numa imposição de uma classificação racial/étnica da população mundial como pedra angular desse padrão de poder". (QUIJANO, 2007, p. 93) Também nos dá informações para questionarmos os supostos conhecimentos universais europeus e nos propõe radicalizar nas abordagens de conteúdos latino-americanos, africanos e indígenas.

Esta colonialidade do poder mundial, ao se impor, subalterniza, invisibiliza povos e culturas, saberes e epistemes. A colonialidade do saber nos faz pensar que o único 
tempo, histórias e culturas possíveis são as derivadas do mundo europeu. Que não existem saberes, conhecimentos e culturas para além da Europa. Esta colonialidade não nos permite enxergar conhecimentos e saberes nos povos indígenas, africanos, afro-brasileiros, ribeirinhos, quilombolas e do campo, por exemplo. Impõe-nos e nos conduz a uma única suposta racionalidade: a europeia. Neste sentido, Oliveira (2012, p. 50) afirma que

o colonizador destrói o imaginário do outro, invisibilizando-o e subalternizando-o enquanto reafirma o próprio imaginário. Assim, a colonialidade do poder reprime os modos de produção de conhecimento, os saberes, o mundo simbólico, as imagens do colonizado e impõem novos. Opera-se então a naturalização do imaginário do invasor europeu, a subalternização epistêmica do outro não europeu e a própria negação e esquecimento de processos históricos não europeus. Essa operação pode se realizar sob várias formas como pela sedução, pela cultura colonialista e o fetichismo cultural que o europeu cria em torno de sua cultura realizando uma verdadeira aspiração pela cultura europeia por parte dos sujeitos subalternizados. Portanto, o eurocentrismo não é a perspectiva cognitiva somente do europeu, mas também daqueles do conjunto dos educados sob sua hegemonia.

Essa colonialidade nos invade, nos envolve de maneira brutal, pois nos força a acreditar que o único modelo de pensamento válido é o europeu. Portanto, desta perspectiva, estão invisibilizados os conhecimentos e saberes dos povos indígenas, dos povos afro-brasileiros, dos quilombolas, ciganos, povos do campo, ribeirinhos, entre outros. Isto nos atinge, em cheio: educadores e educadoras, gestores, estudantes que emergimos nesta colonialidade e por isso mesmo, não valorizamos pensamentos outros para além das epistemes eurocêntricas. Dessa maneira, a colonialidade do poder traz em seu bojo a colonialidade do saber. Ou seja, esta colonialidade do saber fundada pela cultura e o mundo acadêmico europeu perpassa todas as instituições do mundo acadêmico latino-americano, chega às escolas e sistemas educativos de todos os países. Para Oliveira (2012, p. 54), temos que subverter essa colonialidade do saber, pois ela: "operou a inferioridade de grupos humanos não europeus do ponto de vista da divisão racial do trabalho. Do salário, da produção cultural e dos conhecimentos".

Para além dessa colonialidade do poder e do saber, a colonialidade também impôs a colonialidade do ser, onde os povos subalternizados impregnaram de tal forma a episteme do europeu que se torna difícil radicalizar e romper com essas formas de conhecimento. O ser humano subalternizado se sente dominado pelo pensamento dominante, 
introjetando de tal forma que não consegue refletir sobre si mesmo.

Oliveira (2012, p.59) exemplifica dizendo que em outros termos "a colonialidade do ser para esses autores se refere à experiência vivida da colonização e seus impactos na linguagem, que responde sobre a necessidade de se explicitar sobre os efeitos da colonialidade na experiência de vida e não somente na vida dos colonizados".

Estas colonialidades (do poder, do saber e do ser) estudadas pelo grupo de pesquisadores latino-americanos - colonialidade/modernidade - impactou e impacta todos nós, pois fomos e continuamos sendo violentados por essas colonialidades nos espaços: educativos, midiáticos, redes sociais, livros, revistas, igreja, etc.

Na educação, sobretudo e, na educação das relações étnico-raciais, em especial, apesar de vislumbramos alguns avanços no trato com as diferenças, com as diversidades e com princípios epistemológicos diferentes do europeu, mesmo assim precisamos avançar muito. Nossos currículos, nossos planos de ensino, nossas aulas compartimentadas ainda privilegiam um tipo de estudante, um tipo de enquadramento curricular que embora tentemos fugir, muitas vezes, nos sentimos pressionados por essa matriz colonial eurocêntrica autoritária. Quantos conhecimentos ainda faltam nas nossas universidades, nos cursos de formação, na mídia impressa e falada, nos livros didáticos sobre as epistemes dos indígenas, dos quilombolas, dos afro-brasileiros? Quantos conhecimentos ainda precisamos adquirir para nos decolonizarmos efetivamente dessa matriz europeia? Como ensinar e estudar história da África para além da Europa?

Vimos pelos questionamentos acima que estudar a cultura afro-brasileira e, em especial, a história do continente africano para cumprirmos a lei e as Diretrizes tem se constituído verdadeiro campo de questionamentos no ensino de história, pois ainda não convivemos sequer com um consenso entre os especialistas de como abordar esse ensino.

A historiadora Claudia Mortari propõe que estudar história africana se constitui um desafio epistemológico e político para todos e todas e nos convida a pensar alguns caminhos para o ensino de história da África. Um primeiro caminho apontado tem sido o de problematizar as Diretrizes e evitar usá-la como a legislação para ainda propagar uma história africana eurocentrada, pois segundo ela,

podemos afirmar que os problemas estão nas características dos currículos que utilizando-se de uma tradição eurocêntrica, ora excluem os conteúdos, ora aborda sob um olhar estereotipado e equivocado e nas dificuldades da inserção das temáticas em sala de aula devido a defasagem na formação docente (MORTARI, 2016, p.44)

Um segundo caminho pensado por Mortari (2016, p. 44) é de pensar quais conteúdos ensinar e nos sugere 
estudar o continente africano na sua diversidade: étnico, cultural, político, social, econômico e nos aponta alguns caminhos como: perceber os aspectos positivos do continente e das sociedades africanas; perceber as populações do continente como sujeitos e, portanto, partícipes e atuantes do processo histórico e não apenas como vítimas passivas; romper com a visão de uma África harmoniosa; evitar a construção de uma identidade africana para todo o continente e por fim, ter claro que adotar a postura citada abaixo para explicar o continente africano é equivocado: a história da África do século XVI ao XIX; a África pré-colonial e África colonial e, amparando-se em M’Bokolo (2003) explica porquê:

o primeiro é anacrônico e errado porque se constitui de uma perspectiva repleta de implicações intelectuais e políticas. Isto porque se coloca como marco temporal, a partir do qual toda a historia africana será pensada, [...] o segundo embora seja um pouco mais adequado que o primeiro, também não é correto porque perpassa a idéia de África encerrada num imobilismo parado no tempo. Este tempo do passado africano é composto por continuidades, mas também por invenções continuas sob formas tantas de adaptações quanto de rupturas radicais. Então qual termo utilizar: eis uma questão a ser discutida em sala de aula, visando apontar que os próprios primados temporais possuem uma história e, portanto, precisam ser problematizados e discutidos. (MORTARI, 2016, p. 46-47)

Por fim, no terceiro caminho, Mortari indica a decolonialidade como a metodologia mais adequada para o ensino da História da África, ou seja,

o desafio atual no campo do ensino e da pesquisa em história das Áfricas é, principalmente romper com a historiografia colonialista, tornando possível a interação global de perspectivas que se relacionam e desconstroem a visão de produções eurocêntricas e colonialistas. A premissa essencial destes novos estudos é a decolonialidade do olhar e, portanto, de abordagem (2016, p. 53)

Portanto, pensamos que uma das metodologias adotadas em sala de aula que poderá atender a demanda da educação das relações étnico-raciais e de ensino de história e cultura africana e afro brasileira pode ser a interculturalidade.

Ainda que soframos as imposições da colonialidade do poder, do saber e do ser, existem outras possibilidades dos estudos de histórias e culturas africanas, afro-brasileiras e indígenas, bem como a educação para as relações étnicorraciais em sala de aula que rompa com paradigmas e 
modelos eurocentrados de conhecimento bem como as metodologias e práticas tradicionalmente aceitas nos meios educacionais.

Tais procedimentos didático-metodológicos poderão vir acompanhados de um rompimento com as epistemologias eurocentradas se adotarmos os referenciais teóricos da interculturalidade critica, que "opõe-se ao sistema político e econômico neoliberal e considera a educação intercultural como direito e meio para contribuir com a transformação da condição subalterna das minorias". (SILVA; FERREIRA; DA SILVA, 2013, p.258).

Por interculturalidade entende-se a noção de um estilo de vida e de convívio com as diversas culturas que compõe o espaço escolar, mas a educação intercultural vai além do simples convívio. Ela pressupõe respeito, compartilhamento, harmonia, diálogo entre docentes, estudantes e demais componentes do ambiente escolar, nas suas mais diferentes identidades: de gênero, sexo, etnia, geracional, etc.

Porém, na grande maioria das escolas, não existe essa educação intercultural, pois as diversas culturas estudantis são abafadas por práticas e procedimentos pedagógicos e didáticos hegemônicos e homogeneizados no âmbito da escola, ou seja,

termina por criar uma cultura escolar padronizada, ritualística, formal, pouco dinâmica e que enfatiza processos de mera transferência de conhecimentos, quando este de fato acontece e está referida à cultura de determinados atores sociais, brancos, de classe média, de extrato burguês e configurado pela cultura ocidental considerada universal. (CANDAU, 2013, p.53)

Neste sentido, a prática efetiva do que acontece nas escolas está nos limites daquilo que Candau (2000) chamou de cultura escolar. Porém, para além da cultura escolar é pertinente que a escola dialogue com a cultura da escola que são tudo aquilo que os estudantes, professores e funcionários trazem de seu ambiente social para dentro da escola.

Neste sentido, a proposta intercultural prevê que a educação contemple além da cultura escolar, também a cultura da escola, pois só assim a educação e o ensino se farão plural, heterogêneos, diversos, pois mais uma vez retornamos a Souza e Fleuri (2003) e Fleuri (2000) para dizer que a educação intercultural, em resumo, propõe

uma relação que se dá não abstratamente, mas entre pessoas concretas. Entre sujeitos que decidem construir contextos e processos de aproximação, de conhecimento recíproco e de interação. [...] A perspectiva intercultural de educação, enfim, implica mudanças profundas na prática educativa [...] pela necessidade de oferecer oportunidades educati- 
vas à todos respeitando e incluindo a diversidade de sujeitos e de seus pontos de vista. Pela necessidade de desenvolver processos educativos, metodologias e instrumentos pedagógicos que deem conta da complexidade das relações humanas entre indivíduos e culturas diferentes. E pela necessidade de reinventar o papel e o processo de formação de educadores. (FLEURI, 2000, p. 78)

Detalhando um pouco mais a proposta apresentada por Fleuri, focalizamos aqui apoiados em Candau (2013, p.56), inspirada em Jordán (1996) o que é uma educação intercultural e o que ela não é. A educação intercultural não é algo com pouca incidência sobre práticas cotidianas, como também não se refere a um conjunto de atividades escolares esporádicas e muito menos a apresentações de palestras ou espetáculos como apresentação de danças, músicas, vídeos, etc. sobre diferentes culturas e em especial, projetado em datas específicas, como "Semana da Consciência Negra" ou "Dia do Índio". Também não é uma prática para ser aplicada em escolas onde estejam um número significativo de "alunos diferentes" e nem muito menos a integração de disciplinas do currículo escolar.

Percebe-se, portanto, que uma educação intercultural é muito mais complexa do que se imagina. Porém, algumas pistas nos são oferecidas e reflitamos ainda com Candau (2013, p. 58-59), que uma educação intercultural pressupõe necessariamente uma integração entre a pedagogia escolar e as comunidades inseridas naquilo que podemos chamar de pedagogia social, a interculturalidade reconhece e valoriza a diversidade cultural, oferecendo as mesmas oportunidades educacionais atendente as diferentes identidades, perseguindo a necessidade da mais ampla igualdade e democracia. Pressupõe uma transformação profunda em todo o processo educativo, inclusive em cada uma das escolas e em cada sistema de ensino e uma educação que afete todos e todas no ambiente escolar e envolvendo todos os segmentos que convivem na escola, num entrelaçamento de saberes, conhecimentos e vivências.

Percebe-se, portanto, que a escola é espaço amplo, multifacetado, que contempla profundamente a cultura escolar, mas que emerge do seu interior a cultura da escola constituída pelos diversos sujeitos que compõem esses espaços, em especial crianças, adolescentes e jovens brancos, índios, ciganos, negros, entre outros. Dentre estes sujeitos que compõe a cultura da escola, as crianças, adolescentes e jovens negros sempre tiveram suas histórias e memórias silenciadas e negadas. Durante séculos o que vigorou foi um completo apagamento das histórias e culturas africanas e afro-brasileiras no espaço escolar. Por isso hoje, se faz urgentemente necessário dialogar com essas histórias, memórias e culturas no espaço escolar e para além dos moldes eurocêntricos e monoculturais, mas sim um diálogo pautado na perspectiva intercultural e antirracista. Mas, como é 
possível promover uma educação intercultural e antirracistas se instituições escolares, na sua maioria, predominantemente de viés eurocêntrico, sem propormos pedagogias mais problematizadoras, abertas ao diálogo com os diferentes sujeitos que compõe a escola, em suma, como fazer uma educação democrática e crítica e, em especial, uma educação decolonial?

Para se pensar uma educação decolonial, deve-se compreender a interculturalidade muito mais que um novo enfoque pedagógico, mas sim como um "processo e projeto político" (FERNANDES, 2010, p.25). Projeto político este que pode se aproximar com a Lei 10.639/2003 bem como as Diretrizes Curriculares Nacionais para a Educação das Relações Étnico-raciais e para o Ensino de História e Cultura Afro-brasileira, Africana e Indígena. A lei e as Diretrizes propõe que se aborde em salas de aula - e agora como obrigatoriedade - as histórias e culturas africanas, afro-brasileiras e indígenas, pautados em outras lógicas, bem como outras formas de ensino-aprendizagem descentrado da matriz eurocêntrica, contemplando as populações africanas, afro-brasileiras e indígenas. Portanto, o professor ao desenvolver outras práticas pautadas em paradigmas diferentes das do mundo europeu e trazendo outras perspectivas educacionais e formulando epistemologias outras, tem a possibilidade de criar espaços epistemológicos interculturais e pedagogias decoloniais diferentes da eurocentradas.

O professor ao fazer isso estará contemplando em suas aulas, em seu planejamento anual ou em seu plano de ensino, outras histórias e outras subjetividades que poderão favorecer a autoestima e a autoafirmação de populações subalternizadas como de afro-brasileiros e indígenas. Concluímos, portanto, com Oliveira (2010, p.37) que para além de

uma luta decolonial do poder e do saber, para os afro-descendentes a colonialidade do ser é fator relevante nas disputas epistêmicas no capo educacional. Neste sentido, [...] é possível afirmar que as disputas em torno da lei 10.639/2003 no campo educacional além de apresentar caráter epistemológico e político, também se caracterizam como um projeto de "existência e de vida".

Com isso, acreditamos dar um passo a mais no ensino de História e cultura africana e afro-brasileira vinculados à educação para as relações étnico-raciais, por meio de uma proposta de educação que se encaminhe para a promoção de uma sociedade mais justa, menos desigual, solidificando assim os encaminhamentos propostos nos documentos oficiais. 


\section{Referências}

BITTENCOURT, Circe Maria Fernandes. Os confrontos de uma disciplina escolar: da história sagrada à história profana. Revista Brasileira de História. São Paulo, v.13, n. 25/26, p. 193-221, set.92/ago.1993.

BORGES, Jorgeval Andrade. A vez da História da África? O ensino de história africana em escolas públicas da Bahia. Tese (Doutorado em Educação). Universidade Federal da Bahia. Faculdade de Educação. Salvador, 2014. 316 f.

CAIMI, Flávia Eloisa. Conversas e controvérsias: o ensino de história no Brasil (1980 - 1998). Passo Fundo: UPF, 2001, $208 \mathrm{p}$.

CANDAU, Vera Maria (Org.) Reinventar a escola. Petrópolis, RJ: Vozes, 2013.

CANDAU, Vera Maria. (Org.) Ensinar e aprender: sujeitos, saberes e pesquisa. Encontro Nacional de Didática e Prática de Ensino. ENDIPE, Rio de Janeiro. DP\&A, 2000.

CARDOSO, Lourenço. Branquitude acrítica e crítica: a supremacia racial e o branco anti-racista. Revista Latino Americana de Ciências Sociais. Vol.8, pp. 607 - 630, 2010.

CARDOSO, Lourenço; MULLER, Tânia Mara Pedroso. (Org.). Branquitude: estudos sobre a identidade branca no Brasil. Curitiba: Appris editora, 2017, 335 p.

CAVALLEIRO, Eliane (Org.). Racismo e anti-racismo na educação: repensando nossa escola. São Paulo: Selo Negro, 2001.

DOMINGUES, Petrônio José. O mito da democracia racial e a mestiçagem em São Paulo no pós-abolição (1889 - 1930). Tempos históricos. Vol. 5/6, ano. 2003/2004, pp. 275-292.

FERNANDES, Florestan. A integração do negro na sociedade de classes. $3^{\text {a }}$ Ed. São Paulo: Globo, 2008.

FLEURI, Reinaldo Matias. Multiculturalismo e interculturalismos nos processos educativos. In: CANDAU, Vera Maria. (Org.) Ensinar e aprender: sujeitos, saberes e pesquisa. Encontro Nacional de Didática e Prática de Ensino. ENDIPE, Rio de Janeiro. DP\&A, 2000.

FLEURI, Reinaldo Matias. (Org.). Educação intercultural: mediações necessárias. DP \& A editora, 2003.

FREYRE, Gilberto. Casa-grande \& senzala: formação da família brasileira sob o regime de economia patriarcal. 
51 $1^{\text {a }}$ Edição, Global Editora: São Paulo, 2006. $9^{\text {a }}$ Reimpressão, 2016.

GOMES, Nilma Lino. Educação e relações raciais: refletindo sobre algumas estratégias de atuação. In: MUNANGA, Kabengele. (Org.). Superando o racismo na escola. $2^{\text {a }}$ ed. Brasília: MEC/SECAD, 2008. 200 p.

GOMES, Nilma Lino. A questão racial nas escolas: desafios colocados pela implementação da Lei 10.639/2003. In: MOREIRA, Antonio Flávio, CANDAU, Vera Maria. (Org.). Multiculturalismo: diferenças culturais e práticas pedagógicas. $10^{\mathrm{a}}$ ed. Petrópolis, RJ: Vozes, 2013,

HASENBALG, Carlos. Discriminação e desigualdades raciais no Brasil. $2^{\text {a }}$ ed. Belo Horizonte: Ed. Da UFMG, Rio de Janeiro, IUPERJ, 2005.

HASENBALG, Carlos A; SILVA, Nelson do Valle. Raça e oportunidades educacionais no Brasil. Estudos Afro-asiáticos. $\mathrm{n}^{0}$ 18, p. 269 - 290, 2006.

M'BOKOLO, Elikia. África negra. História e civilização até o século XVIII. Lisboa: Vulgata, 2003.

MEYER, André Felipe. Um click na Tekoá: elaboração de um site de produção de narrativas audiovisuais através de fontes guarani. Dissertação (Mestrado Profissional em Ensino de História). Centro de Ciências Humanas e da Educação. Universidade do Estado de Santa Catarina. Udesc. Florianópolis, 2017. 255 p.

MIRANDA, Allan Vinicius Ferreira, TOLEDO, Maria Thereza, ANDRADE, Vanessa Menezes de. Racismo brasileiro: a cultura da percepção seletiva em nossa visão psicológica e social. Revista Dissertar. Ano 14, vol. 1, no 28/29, pp. $54-64$, abril/2018

MORTARI, Cláudia. O “equilíbrio das histórias": reflexões em torno de experiências de ensino e pesquisa em História das Áfricas. In: PAULA, Simoni Mendes de, SOUZA, Silvio Marcus Correa. (Org.). Nossa África: ensino e pesquisa. São Leopoldo. Oikos, 2016.

OLIVEIRA, Luiz Fernandes. História da África e dos africanos na escola: as perspectivas para a formação dos professores de história quando a diferença se torna obrigatoriedade curricular. Tese (Doutorado em Educação). Departamento de Educação do Centro de Teologia e Ciências Humanas. Pontifícia Universidade Católica do Rio de Janeiro. Rio de Janeiro, 2010. $281 \mathrm{f}$.

OLIVEIRA, Luiz Fernandes. História da África e dos africanos na escola: desafios políticos, epistemológicos e identitários para a formação dos professores de História. Rio de Janeiro: Imperial Novo Milênio, 2012, 320 p. 
PASSOS, Joana Célia dos. As relações étnico-raciais nas licenciaturas: o que dizem os currículos anunciados. Poiésis. Revista do Programa de Pós-graduação em Mestrado em Educação. Vol. 8, n ${ }^{0} 13$, p. 172 - 178, jan/jun. 2014.

PAULA, Benjamim Xavier de. A educação para as relações étnico-raciais e o estudo da história e cultura da África e afro-brasileira: formação, saberes e práticas educativas. Tese (Doutorado em educação). Faculdade de Educação - FACED. Universidade Federal de Uberlândia. Uberlândia, MG, 2013. 327 f.

PEREIRA, Paula de Abreu. A educação das relações étnico-raciais: experiência numa escola pública de Santa Catarina. Dissertação (Mestrado em Educação). Centro de Ciências da Educação. Universidade Federal de Santa Catarina. Florianópolis, 2011. 318p.

PEREIRA, Amilcar Araújo. Por uma autêntica democracia racial: os movimentos negros nas escolas e nos currículos de história. Revista História Hoje. Vol. 1, $\mathrm{n}^{0}$ 1, pp. 111 $-128,2012$.

PEREIRA, Acácia Regina. Currículo de História na formação da identidade e memória. In: XXIX Simpósio nacional de História: contra os preconceitos-História e democracia. Brasília: UNB, 24-29/jul. 2017.

QUIJANO, Anibal. Colonialidad de 1 poder y classificación social: CASTRO GOMES, Santiago; GROSFOGUEL, Ramón. (Orgs). El giro decolonial: reflexiones para uma diversidad epistêmica, mas allá del capitalismo global. Bogotá: Universidade Javeriana - Instituto Pensar/Universidade Central - IESCO/Siglo del Hombres editores, 2007, p. $93-126$.

QUIJANO, Anibal. Colonialidade do poder e classificação social. In: SANTOS, Boaventura de Sousa, Meneses, Maria Paula. (Orgs.). Epistemologias do Sul. São Paulo: Cortez, 2010, $637 \mathrm{p}$.

RODRIGUES, Ruth Meyre Mota. Educação das relações étnico-raciais e gestão educacional. In: XV Simpósio Brasileiro e II Simpósio Ibero-Americano de Política e Administração da Educação: construção histórica, debates contemporâneos e novas perspectivas. ANPAE, São Paulo, SP, 26 - 29 de abril/2011. Disponível em: http:// www.anpae.org.br/simposio2011/cdrom2011/PDFs/trabalhosCompletos/comunicacoesRelatos/0480.pdf. Acesso em 09/07/2018.

SANTOS, Lorene dos. Saberes e práticas em redes de trocas: a temática africana e afro-brasileira em questão. Tese (Doutorado em educação). Faculdade de educação. Universidade Federal de Minas Gerais. Belo Horizonte, Minas Gerais, 2010. 334 f. 
SCHUCMAN, Lia Vainer. Entre o encardido, o branco e o branquíssimo: branquitude, hierarquia e poder na cidade de São Paulo. São Paulo: Annablume, 2014, 194 p.

SILVA, Petronilha Beatriz Gonçalves e. Aprender, ensinar e relações étnico-raciais no Brasil. In: FONSECA, Marcus Vinicius, SILVA, Carolina Mostaro Neves da, FERNANDES, Alexandra Borges (Org.). Relações étnico-raciais e educação no Brasil. Belo Horizonte: Mazza edições, 2011, 216 p.

ZILIOTTO, Bruno. Provocações crônicas: a construção de um site educativo para repensar a escola, a disciplina de História e as Áfricas. Dissertação (Mestrado Profissional em Ensino de História). Centro de Ciências Humanas e da Educação. Universidade do Estado de Santa Catarina. UDESC. Florianópolis, 2016, 126 p.

Recebido em: 01/08/2018 Aprovado em: 19/12/2018 Publicado em: 31/12/2018 